\title{
Assessment of mechanical and wear properties of epoxy-based hybrid composites
}

\author{
Agunsoye, J.O. ${ }^{a}$, Bello, S.A. ${ }^{\mathrm{a}, \mathrm{b},{ }^{*},}$, Bello, L. ${ }^{\mathrm{a}}$, Idehenre, M.M. ${ }^{\mathrm{a}}$ \\ ${ }^{a}$ Department of Metallurgical and Materials Engineering, University of Lagos, Akoka, Yaba, Lagos Nigeria \\ ${ }^{b}$ Department of Materials Science and Engineering, Kwara State, University, Malete, Kwara State Nigeria
}

\begin{abstract}
A B S T R A C T
Discarded florescent tubes and graphite rods obtained from dumped primary cells have been processed to obtain glass and graphite particles. $80 \mu \mathrm{m}$ glass and graphite particles were used as reinforcements in epoxy resin, LY 556 cured with HY 931 hardener to produce epoxy resin hybrid composites. The morphology, mechanical properties, thermal stability and wear resistance characteristics of the epoxy resin glass/graphite hybrid composites were studied. The thermogravimetric analyser TGA 701 was used to examine the thermal stability of the epoxy resin glass particle/graphite composites. Addition of graphite and glass particles enhanced the strength, thermal stability and wear resistance of the epoxy resin. However, tensile strain and impact energy absorption of the epoxy resin hybrid composites started declining at 6 wt $\%$ of glass particle addition. The increase in wear rate of the composites with an increment in applied loads is attributable to increase in the normal reaction between the examined sample surfaces and the emery paper. Furthermore, the increase in wear resistance with an increment in wt $\%$ of glass particle additions is attributable to good interfacial adhesion between matrix and the fillers. The textural and appearance differences between the scanning electron micrographs of the control and epoxy resin hybrid composites is attributable to the presence of new phases due to exothermic and cross linking reaction between the matrix and the fillers. Hence, new vital engineering composites peculiar to automobile, aerospace and building industries have been produced.
\end{abstract}

\section{ARTICLE INFO}

Keywords:

Epoxy resin

Composite

Glass particle

Graphite particle

Mechanical properties

Wear properties

${ }^{*}$ Corresponding author: sefiu.bello@kwasu.edu.ng; adekunle_b@yahoo.com (Bello, S.A.)

Article history:

Received 11 June 2015

Revised 8 January 2016

Accepted 19 January 2016 


\section{References}

[1] Bello, S.A., Agunsoye, J.O., Hassan, S.B., Kana, M.G.Z., Raheem, I.A. (2015). Epoxy resin based composites, mechanical and tribological properties: A review, Tribology in Industry, Vol. 37, No. 4, 500-524.

[2] Marieta, C., Schulz, E., Irusta, L, Gabilondo, N., Tercjak, A., Mondragon, I. (2005). Evaluation of fiber surface treatment and toughening of thermoset matrix on the interfacial behaviour of carbon-reinforced cyanate matrix composites, Composite Science Technology, Vol. 65, No. 14, 2189-2197, doi: 10.1016/i.compscitech.2005.05.008.

[3] Marieta, C., Schulz, E., Mondragon, I. (2002). Characterization of interfacial behaviour in carbon-fibre/cyanate composites, Composites Science and Technology, Vol. 62, No. 2, 299-309, doi: 10.1016/S0266-3538(01)00215-9.

[4] Wang, Y., Hahn, T.H. (2007). AFM Characterization of the interfacial properties of carbon fiber reinforced polymer composites subjected to hydrothermal treatments, Composites Science and Technology, Vol. 67, No. 1, 92101, doi: 10.1016/i.compscitech.2006.03.030.

[5] Donnet, J.B., Bansal, R.C. (1990). Carbon Fibers, (2nd edition), Mercel Dekker, New York.

[6] Moutier, J., Fois, M., Picard, C. (2009). Characterization of carbon/epoxy materials for structural repair of carbon/BMI structures, Composites: Part B, Vol. 40, No. 1, 1-6, doi: 10.1016/j.compositesb.2008.09.003.

[7] Feraboli, P., Masini, A. (2004). Development of carbon/epoxy structural components for a high performance vehicle, Composites: Part B, Vol. 35, No. 4, 323-330, doi: 10.1016/i.compositesb.2003.11.010.

[8] Davoodi, M.M., Sapuan, S.M., Ahmad, D., Aidy Ali, Khalina, A., Jonoobi, M. (2010). Mechanical properties of hybrid kenaf/glass reinforced epoxy composite for passenger car bumper beam, Materials \& Design, Vol. 31, No. 10, 4927-4932, doi: 10.1016/i.matdes.2010.05.021.

[9] Agunsoye, J.O., Talabi, S.I., Hassan, S.B., Awe, I.O., Bello, S.A., Aziakpono, E. (2014). The development and characterisation of aluminium dross-epoxy resin composite materials, Journal of Materials Science Research, Vol. 3, No. 2, 23-37, doi: 10.5539/jmsr.v3n2p23.

[10] Hassan, S.B., Aigbodion, V.S., Patrick, S.N. (2012). Development of polyester/eggshell particulate composites, Tribology in Industry, Vol. 34, No. 4, 217-225.

[11] Allaoui, A., Bai, S., Cheng, H.M., Bai, J.B. (2002). Mechanical and electrical properties of a MWNT/epoxy composite, Composites Science and Technology, Vol. 62, No. 15, 1993-1998, doi: 10.1016/S0266-3538(02)00129-X.

[12] Valášek, P., Müller, M., Hloch, S. (2015). Recycling of corundum particles - two-body abrasive wear of polymeric composites based on waste, Tehnički vjesnik - Technical Gazette, Vol 22, No. 3, 2015, 567-572, doi: 10.17559/TV20131111140048.

[13] Parkinson, M., Visco, C. (2002). Sustainable markets for waste glass from fluorescent tubes and lamps, Final Report, The National Centre for Business and Sustainability (NCBS), Manchester, UK.

[14] Hassan, S.B., Agunsoye, J.O., Bello, S.A. (2015). Ball milling synthesis of Al (1050) particles: Morphological study and particle size determination, Industrial Engineering Letters, Vol. 5, No. 11, 22-27.

[15] Bello, S.A., Agunsoye, J.O., Hassan, S.B. (2015). Synthesis of coconut shell nanoparticles via a top down approach: Assessment of milling duration on the particle sizes and morphologies of coconut shell nanoparticles, Materials Letters, Vol. 159, 514-519, doi: 10.1016/i.matlet.2015.07.063.

[16] Bello, S.A., Hassan, S.B., Agunsoye, J.O., Kana, M.G.Z., Raheem, I.A. (2015). Synthesis of uncarbonised coconut shell nanoparticles: Characterisation and particle size determination, Tribology in Industry, Vol. 37, No. 2, 257-263.

[17] Bello, S.A., Raheem, I.A., Raji, N.K. (2015). Study of tensile properties, fractography and morphology of aluminium $(1 \mathrm{xxx})$ /coconut shell micro particle composites, (In Press), Journal of King Saud University - Engineering Sciences, doi: $10.1016 /$ i.j.jksues.2015.10.001. 


\title{
Ovrednotenje mehanskih in obrabnih lastnosti epoksidnih hibridnih kompozitov
}

\author{
Agunsoye, J.O. ${ }^{a}$, Bello, S.A. ${ }^{\mathrm{a}, \mathrm{b},{ }^{*},}$, Bello, L. ${ }^{\mathrm{a}}$, Idehenre, M.M. ${ }^{\mathrm{a}}$ \\ ${ }^{a}$ Department of Metallurgical and Materials Engineering, University of Lagos, Akoka, Yaba, Lagos Nigeria \\ ${ }^{\mathrm{b}}$ Department of Materials Science and Engineering, Kwara State, University, Malete, Kwara State Nigeria
}

\begin{abstract}
POVZETEK
Za izdelavo steklenih in grafitnih delcev smo uporabili opuščene cevi fluorescentnih sijalk in grafitne palice. Za učvrstitev epoksidne smole LY 556 smo uporabili steklene in grafitne delce velikosti $80 \mu \mathrm{m}$, ki smo jo prepojili s trdilcem HY 931. S tem smo dobili epoksidni hibridni epoksidni kompozit steklo/grafit, ki smo mu ugotavljali morfologijo, mehanske lastnosti, termično stabilnost in odpornost na obrabo. Za ugotavljanje termične stabilnosti kompozita smo uporabili termogravimetričen preizkuševalec TGA 701. Dodatek grafita in stekla je povečal čvrstost, termično stabilnost in odpornost na obrabo epoksidnega kompozita, vendar pa sta se natezni raztezek in absorpcija udarne energije hibridnega epoksidnega kompozita začela zmanjševati pri 6 wt\% (masnega deleža) steklenih delcev. Povečanje obrabe kompozitov s povečanjem obremenitve lahko pripišemo povečani reakcijski sili med proučevano površino vzorca in smirkovim papirjem. Povečana odpornost na obrabo s povečanjem wt\% (masnega deleža) steklenih delcev je posledica dobrih adhezijskih lastnosti med epoksidno osnovo in polnilom. Razlike med teksturnimi značilnosti in videzom med kontrolnimi vzorci in hibridnimi epoksidnimi kompoziti, ugotovljenimi s pomočjo elektronskega skeniranja, kažejo na navzočnost nove faze, ki je posledica eksotermnih prepletajočih se reakcij med epoksidno osnovo in polnilom. Na ta način smo razvili nove kompozite za inženirsko prakso, ki so primerni za uporabo v avtomobilski in letalski industriji in tudi za konstrukcijske namene.
\end{abstract}

\section{PODATKI O ČLANKU}

Ključne besede: Epoksidna smola Kompozit

Stekleni delci

Grafitni delci

Mehanske lastnosti

Obrabne lastnosti

*Kontaktna oseba: sefiu.bello@kwasu.edu.ng; adekunle_b@yahoo.com (Bello, S.A.)

Zgodovina članka:

Prejet 11. junija 2015

Popravljen 8. januarja 2016

Sprejet 19. januarja 2016 